\title{
Invasive Candida Infection with Ureteral Obstruction
}

\author{
Yoshitaka Tomoda $^{1}$, Yasuyuki Kihara ${ }^{2}$, Ryoji Kouzuma ${ }^{2}$ and Kazutoyo Tanaka ${ }^{1}$
}

Key words: Candida tropicalis, ureteral obstruction, renal papillary necrosis, acute kidney injury

(Intern Med 57: 1499-1500, 2018)

(DOI: 10.2169/internalmedicine.0105-17)
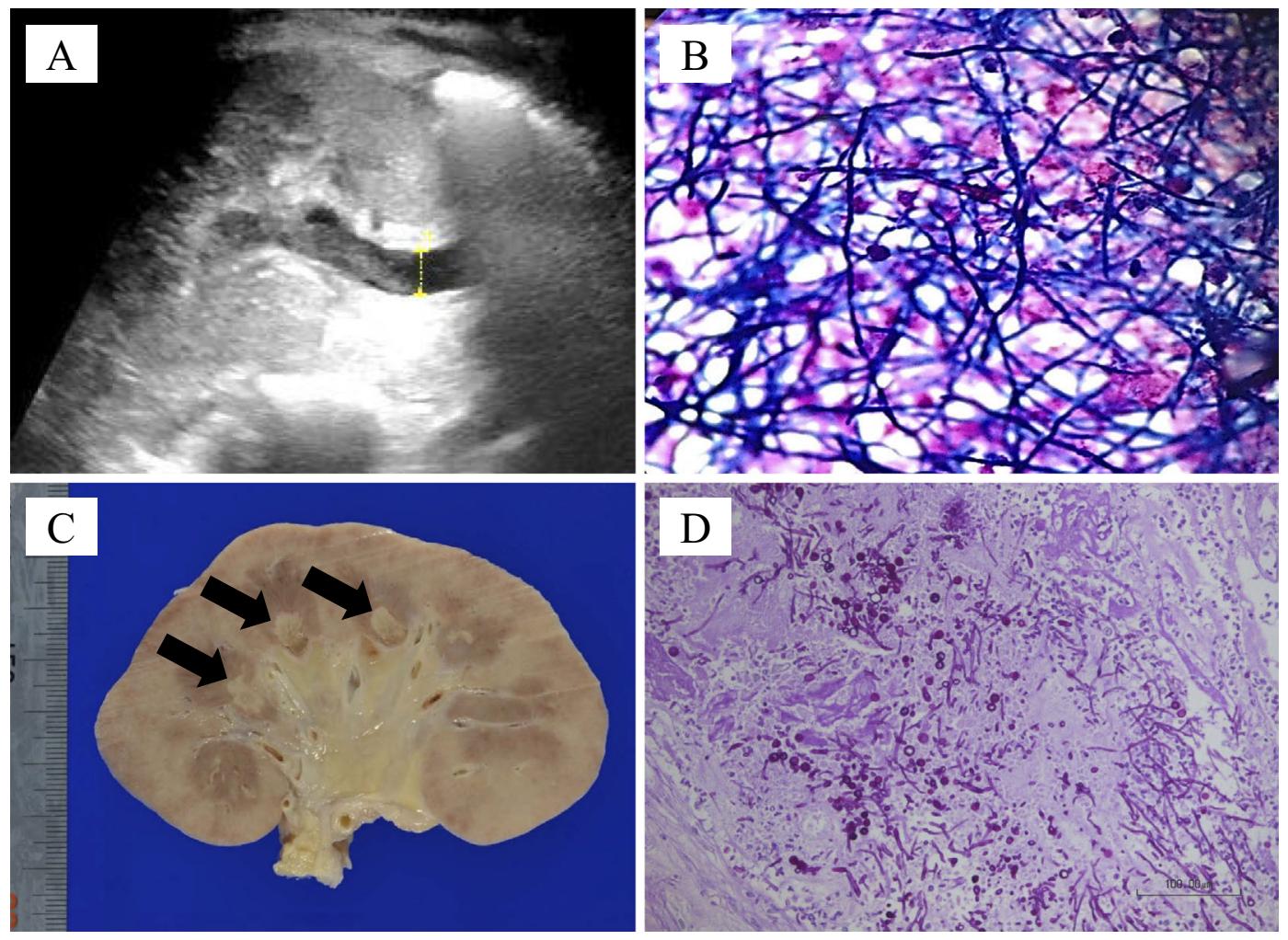

Picture.

A 63-year-old man with a previous cerebral infarction was admitted to our hospital due to persistent abdominal discomfort. His serum creatinine $(2.47 \mathrm{mg} / \mathrm{dL})$ and blood urea nitrogen $(144.2 \mathrm{mg} / \mathrm{dL})$ levels were elevated. Abdominal ultrasonography revealed bilateral dilated ureters with hyperechoic material (Picture A). Double-J stents were placed in both ureters, after which his serum creatinine level improved. Ureteroscopy revealed that both ureteral lumens were obstructed with white, viscous, purulent urine. Subsequent blood and urine cultures confirmed the presence of Candida tropicalis (Picture B) that was susceptible to flu- conazole. The patient was treated with fluconazole, but he died due to pneumonia on hospital day 55. During the autopsy, a gross examination of the kidneys revealed multiple foci of papillary necrosis (Picture C). A histological analysis revealed the infiltration of neutrophils and fungal filaments within the necrotic area (Picture D). Urinary tract obstruction due to mucous debris and agglutination of renal papillary necrotic tissue is a rare complication of candiduria (1).

The authors state that they have no Conflict of Interest (COI).

${ }^{1}$ Department of General Medicine, Saiseikai Fukuoka General Hospital, Japan and ${ }^{2}$ Department of General Internal Medicine, Kitakyushu General Hospital, Japan

Received: August 21, 2017; Accepted: September 26, 2017; Advance Publication by J-STAGE: December 27, 2017

Correspondence to Dr. Yoshitaka Tomoda, yoshisoph@gmail.com 


\section{Reference}

1. Kauffman CA, Fisher JF, Sobel JD, et al. Candida urinary tract infections-diagnosis. Clin Infect Dis 52: 452-456, 2011.
The Internal Medicine is an Open Access article distributed under the Creative Commons Attribution-NonCommercial-NoDerivatives 4.0 International License. To view the details of this license, please visit (https://creativecommons.org/licenses/ by-nc-nd/4.0/).

(C) 2018 The Japanese Society of Internal Medicine Intern Med 57: 1499-1500, 2018 